\title{
The activity of a metronidazole analogue and its $\beta$-cyclodextrin complex against Trypanosoma cruzi
}

\author{
Marcela Silva Lopes ${ }^{1}$, Policarpo Ademar Sales Júnior², Amanda Gervásio Ferreira Lopes', \\ Maria Irene Yoshida ${ }^{3}$, Thais Horta Alvares da Silva', Alvaro José Romanha², \\ Ricardo José Alves ${ }^{1}$, Renata Barbosa de Oliveira ${ }^{1 /+}$
}

\begin{abstract}
${ }^{1}$ Departamento de Produtos Farmacêuticos, Faculdade de Farmácia ${ }^{3}$ Departamento de Química, Instituto de Ciências Exatas, Universidade Federal de Minas Gerais, Belo Horizonte, MG, Brasil ${ }^{2}$ Instituto de Pesquisas René Rachou-Fiocruz, Belo Horizonte, MG, Brasil

In this study we prepared an inclusion complex between an iodide analogue of metronidazole (MTZ-I) and cyclodextrin (CD) to develop a safer and more effective method of treating Trypanosoma cruzi infections. According to our results, MTZ-I and MTZ-I: $\beta$-CD were 10 times more active than MTZ, demonstrating that the presence of an iodine atom on the side chain increased the trypanocidal activity while maintaining its cytotoxicity. The selective index shows that MTZ-I was 10 times more active against $\mathrm{T}$. cruzi than it was against mammalian cells. The modification of MTZ side chains provides a promising avenue for the development of new drugs.
\end{abstract}

Key words: nitroaromatic - cyclodextrin - Chagas disease - Trypanosoma cruzi

Chagas disease is a potentially life-threatening illness caused by the flagellate protozoan Trypanosoma cruzi. In Brazil, benznidazole is the only drug available for the treatment of Chagas disease, but it has toxic side effects and is only active in the acute phase of the illness (Urbina 1999). With such an unfavourable treatment, the development of new drugs to fight Chagas disease becomes increasingly important.

Because nitroaromatics have been found to be active against T. cruzi (Maya et al. 2003), we decided to evaluate the trypanocidal activity of a metronidazole (MTZ) analogue [1-(2-iodoethyl)-2-methyl-5-nitroimidazole (MTZ-I)] (Fig. 1) previously synthesised in our laboratory (Busatti et al. 2007) and its beta-cyclodextrin ( $\beta-C D)$ inclusion complex. We also investigated the differences in toxicity between free MTZ-I and its $\beta$-CD inclusion complex. It has been well demonstrated that inclusion complexes decrease the toxic effect of some therapeutic agents (Corrêa et al. 2005). Furthermore, the complexation of MTZ-I with CD may improve the bioavailability of MTZ-I by enhancing its water solubility.

The solubility of the complex was evaluated in relation to MTZ-I with a phase solubility study. The phase solubility diagram of MTZ-I and $\beta-C D$ was obtained by plotting the changes in guest solubility as a function of $\beta-C D$ concentration. The solubility curve can be classified as a $\mathrm{B}_{\mathrm{s}}$ curve according to Higuchi and Connors (1965). The complex exhibits higher solubility than the guest molecule, but its limit was reached within the $\mathrm{CD}$ concentration ranges that were tested. Increasing the

Financial support: FAPEMIG, CNPq

+ Corresponding author: renatabo@farmacia.ufmg.br

Received 28 March 2011

Accepted 9 August 2011 amount of available CD-molecules did not lead to a rise in solubility. However, the MTZ-I solubility increased considerably with an equimolar ratio of MTZ-I: $\beta-C D$.

The solid-state inclusion complex was characterised using infrared (IR) spectroscopy and differential scanning calorimetry (DSC). A comparison between the IR spectra of MTZ-I, $\beta$-CD, MTZ-I and $\beta$-CD in a simple 1:1 physical mixture (PM) and MTZ-I and $\beta-C D$ as a complex shows some significant changes in the shape and position of the absorbance bands of the MTZ-I functional groups. Analysis of the IR spectra of the inclusion complexes revealed the most frequent changes to be in the range of $700-660 \mathrm{~cm}^{-1}$, which were interpreted as the band corresponding to the vibration of the C-I bond. Differences were also found in the 1,526 and $1,356 \mathrm{~cm}^{-1}$ regions, which were attributed to the skeleton vibrations of the $\mathrm{C}-\mathrm{NO}_{2}$ group. Less pronounced changes were observed in the IR spectrum of the PM. The DSC thermal behaviours of MTZ-I, $\beta-C D$, the MTZ-I: $\beta$-CD complex and the MTZ-I: $\beta-C D$ PM were also studied. The DSC curve for MTZ-I showed a typical pure crystalline substance profile with a sharp endothermic peak at $101.2^{\circ} \mathrm{C}$. The DSC curve of $\beta$-CD showed a broad endothermic peak in the range of $75-85^{\circ} \mathrm{C}$, which can be attributed to desolvation, followed by a small endothermic peak at $220.16^{\circ} \mathrm{C}$. The formation of an inclusion complex was suggested by the absence of a melting endothermic peak for MTZ-I in the DSC curve of the inclusion complexes. The PMs showed three endothermic peaks, two for the $\beta-\mathrm{CD}$ at $75.20^{\circ} \mathrm{C}$ and $217.8^{\circ} \mathrm{C}$, as well as one for the MTZ-I at $103.1^{\circ} \mathrm{C}$.

Molecular modelling was used to help establish the mode of interaction for $\beta$-CD with MTZ-I. In the molecular modelling study, solutions of 100 independent docking runs resulted in four clusters. The most favourable $\Delta \mathrm{G}_{\text {bind }}$ cluster had 36 conformations. The calculated free energy of binding of the lowest energy solution of docking was $-5.63 \mathrm{Kcal} / \mathrm{mol}$. Negative values of $\Delta \mathrm{G}$ indicated that the complex was more thermodynamically stable than the isolated components and that the complex 
assembles spontaneously. The binding position with the lowest energy in the most favourable cluster of $\Delta \mathrm{G}_{\text {tind }}$ values was selected for a more detailed analysis. The MTZ-I adjusted well to the cavity of $\beta-C D$, with an imidazole ring and halogen creating van der Waals interactions and the polar groups interacting with the hydroxyl groups of $\beta$-CD (Fig. 2).

The in vitro trypanocidal effects of pure MTZ-I and the MTZ-I: $\beta-C D$ complex were evaluated against amastigote and trypomastigote forms of $T$. cruzi according to protocols established by Buckner et al. (1996) with modifications (Romanha et al. 2010). The $\beta$-galactosidase Tulahuen strain used was courtesy of Dr Frederick Buckner, University of Washington. Infective trypomastigote forms were obtained through a culture in monolayers of mouse L929 fibroblasts. For the bioassay, 96 well tissue culture microplates were seeded with L929 fibroblasts in $80 \mu \mathrm{L}$ with a density of $4.0 \times 10^{3}$ fibroblasts per well and incubated overnight at $37^{\circ} \mathrm{C}$ and $5 \% \mathrm{CO}_{2} . \beta$-galactosidaseexpressing trypomastigotes in $20 \mu \mathrm{L}$ of medium were then added at a density of $4.0 \times 10^{4}$ per well. After $2 \mathrm{~h}$ of contact, the medium with trypomastigotes that had not penetrated the cells was discarded and replaced by $200 \mu \mathrm{L}$ of fresh medium. After $48 \mathrm{~h}$, the medium was discarded again and replaced by $180 \mu \mathrm{L}$ of fresh medium and $20 \mu \mathrm{L}$ of a solution of MTZ, MTZ-I or MTZ-I: $\beta-C D$ at different concentrations. Each compound was tested in quadruplicate. After seven days of culture development, chlorophenol red $\beta$-D-galactopyranoside at $100 \mu \mathrm{M}$ and Nonidet P-40 at $0.1 \%$ were added to the plates and the plates were then incubated overnight at $37^{\circ} \mathrm{C}$. The absorbance was measured at $570 \mathrm{~nm}$ in an automated microplate reader. Benznidazole at its half maximal inhibi-

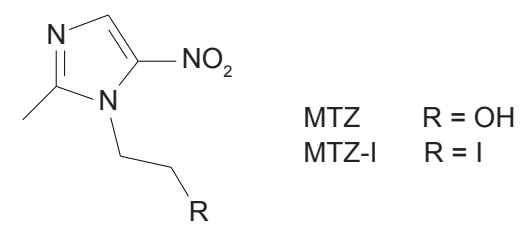

Fig. 1: chemical structures of the metronidazole (MTZ) and the MTZ analogue (MTZ-I).

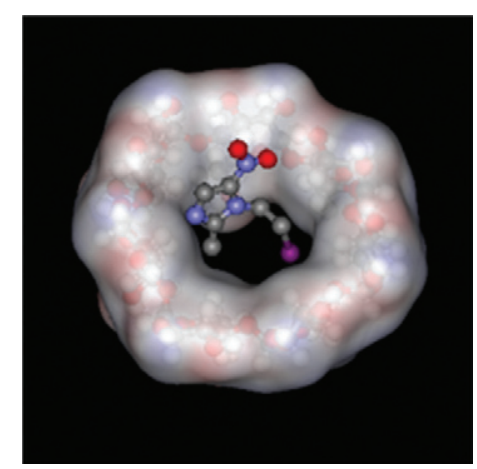

Fig. 2: inclusion complexes between metronidazole analogue and beta-cyclodextrin at the lowest $\Delta \mathrm{G}$ conformation. tory concentration $\left(\mathrm{IC}_{50}\right)(1 \mu \mathrm{g} / \mathrm{mL}=3.81 \mu \mathrm{M})$ was used as a positive control. The results were expressed as the percentage of parasite growth inhibition.

In vitro cytotoxic tests to determine the toxicity of the compounds against L929 cells were also carried out using alamarBlue ${ }^{\circledR}$. The conditions were the same as those described for the $\beta$-galactosidase assay. After $96 \mathrm{~h}$ of exposure to the compounds, the alamarBlue ${ }^{\circledR}$ was added and the absorbance at 570 and $600 \mathrm{~nm}$ was measured after 4-6 h. The cell viability was expressed as the percentage of difference in the reduction between treated and untreated cells (Romanha et al. 2010). Lethal concentration $\left(\mathrm{LC}_{50}\right)$ and $\mathrm{IC}_{50}$ values were calculated using linear interpolation and the selectivity index (SI) was determined based on the ratio of the $\mathrm{LC}_{50}$ value in the host cell to the $\mathrm{IC}_{50}$ value of the parasite $\left(\mathrm{LC}_{50} / \mathrm{IC}_{50}\right.$ ratio) (Table). The activity and toxicity of MTZ was included for comparison. According to results shown in Table, MTZ-I and MTZ-I: $\beta-C D$ were 10 times more active than MTZ, demonstrating that the presence of the iodine atom on the side chain increased the trypanocidal activity while leaving the cytotoxicity unaltered. The SI shows that MTZ-I was at least 10 times more active against $T$. cruzi than against mammalian cells.

The trypanocidal activity of aromatic non-imidazole nitrocompounds was previously described by us (Oliveira et al. 2003). All compounds tested displayed lower activity against trypomastigote forms of $T$. cruzi $\left(\mathrm{IC}_{50}\right.$ $>450 \mu \mathrm{M}$ ) when compared to the activity of MTZ-I $(111 \mu \mathrm{M})$. This may be evidence of the greater effectiveness of nitroimidazoles as trypanocidal agents.

The efficacy of 2 and 5-nitroimidazoles including benznidazole, megazol and nifurtimox on different $T$. cruzi strains was described by Maya et al. (2003) and the $\mathrm{IC}_{50}$ values varied from 3.75-74.99 $\mu \mathrm{M}$ in the Tulahuen strains. These $\mathrm{IC}_{50}$ values were lower when compared

\section{TABLE}

Comparison of trypanocidal activity, cytotoxicity, selectivity index among metronidazole (MTZ), the MTZ analogue (MTZ-I) and its inclusion complex

\begin{tabular}{lccc}
\hline Compound & $\begin{array}{c}\text { Trypanocidal } \\
\text { activity } \\
\mathrm{IC}_{50}(\mu \mathrm{M})^{a} \pm \mathrm{SD}\end{array}$ & $\begin{array}{c}\text { Cytotoxicity } \\
\mathrm{LC}_{50}(\mu \mathrm{M})^{b}\end{array}$ & $\begin{array}{c}\text { Selectivity } \\
\text { index } \\
\mathrm{LC}_{50} / \mathrm{IC}_{50}\end{array}$ \\
\hline MTZ & $1,000 \pm 164.5$ & $>1,000$ & $>1$ \\
MTZ-I & $111 \pm 16.6$ & $>1,000$ & $>9$ \\
MTZ-I: $\beta-\mathrm{CD}$ & $111 \pm 15.8$ & $>1,000$ & $>9$ \\
Benznidazole & 3.81 & $>1,000$ & $>262$ \\
\hline
\end{tabular}

$a$ : compound concentration that inhibits $50 \%$ of the growth of the culture amastigote and trypomastigote forms of Trypanosoma cruzi; $b$ : compound concentration that reduces $50 \%$ of the L929 cell viability measured by the alamarBlue ${ }^{\circledR}$ assay. Trypanocidal and alamarBlue ${ }^{\circledR}$ assay have been repeated two times and are showed the representative data of one experiment. $\mathrm{IC}_{50}$ : half maximal inhibitory concentration; $\mathrm{LC}_{50}$ : lethal concentration; SD: standard deviation; $\beta-\mathrm{CD}$ : beta-cyclodextrin. 
with those obtained for MTZ-I $(111 \mu \mathrm{M})$ in this work. However, the previous authors used the non-infective epimastigote form while we evaluated the effect of MTZ and MTZ-I against trypomastigotes and amastigotes of the Tulahuen T. cruzi line. This can justify the observed differences in activity.

Pure MTZ-I and MTZ-I: $\beta-C D$ exhibited the same trypanocidal activity and toxicity in mammalian cells. However, complexation by inclusion increases MTZ-I solubility in water 1.7 times. The improved solubility of MTZ-I is expected to result in better bioavailability and more predictable trypanocidal activity.

The modification of the MTZ side chain presents a promising avenue for the development of new drugs, as exhibited here as well as in Busatti et al. (2007). The formation of an inclusion complex creates an interesting platform for the delivery of drugs with poor physicochemical and biopharmaceutical properties. However, further studies are necessary to assess the real potential of using these compounds and their derivatives as drugs. The synthesis of other MTZ analogues and their subsequent biological evaluation are presently under investigation.

\section{REFERENCES}

Buckner F, Verlinde CLMJ, La Flamme AC, Van Voorhis WC 1996. Efficient technique for screening drugs for activity against Trypanosoma cruzi using parasites expressing beta-galactosidase. Antim Agents Chemother 40: 2592-2597.
Busatti HGNO, Vieira AED, Viana JC, Silva HE, Souza-Fagundes EM, Martins-Filho AO, Alves RJ, Gomes MA 2007. Effect of metronidazole analogues on Giardia lamblia cultures. Parasitol Res 102: 145-149.

Corrêa DHA, Melo PS, Carvalho CAA, Azevedo MBM, Duran N, Haun M 2005. Dehydrocrotonin and its $\beta$-cyclodextrin complex: cytotoxicity in V79 fibroblasts and rat cultured hepatocytes. Eur J Pharmacol 510: 17-24.

Higuchi T, Connors KA 1965. Phase-solubility techniques. Adv Anal Chem Instr 4: 117-212.

Maya JD, Bollo S, Nuñez-Vergara LJ, Squella JA, Repetto Y, Morello A, Périé J, Chauviére G 2003. Trypanosoma cruzi: effect and mode of action of nitroimidazole and nitrofuran derivatives. Biochem Pharmacol 65: 999-1006.

Oliveira RB, Passos APF, Alves RO, Romanha AJ, Prado MAF, Souza-Filho JD, Alves RJ 2003. In vitro evaluation of the activity of aromatic nitrocompounds against Trypanosoma cruzi. Mem Inst Oswaldo Cruz 98: 141-144.

Romanha AJ, de Castro SL, Soeiro MNC, Lannes-Vieira J, Ribeiro I, Talvani A, Bourdin B, Blum B, Olivieri B, Zani C, Spadafora C, Chiari E, Chatelain E, Chaves G, Calzada JE, Bustamante JM, Freitas-Junior LH, Romero LI, Bahia MT, Lotrowska M, Soares M, Andrade SG, Armstrong T, Degrave W, Andrade ZA 2010. In vitro and in vivo experimental models for drug screening and development for Chagas disease. Mem Inst Oswaldo Cruz 105: 233-238.

Urbina JA 1999. Parasitological cure of Chagas disease: is it possible? Is it relevant? Mem Inst Oswaldo Cruz 94 (Suppl. I): 349-355. 